\title{
Exploring the Macrostructure of Management Forewords of Corporate Annual Reports
}

\author{
Atefeh Mobasher \\ Faculty of Modern Languages, University Putra Malaysia \\ 43400 UPM Serdang, Selangor Darul Ehsan, Malaysia \\ E-mail: atefeh.mobasher@gmail.com \\ Afida Mohamad Ali (Corresponding author) \\ Faculty of Modern Languages, University Putra Malaysia \\ 43400 UPM Serdang, Selangor Darul Ehsan, Malaysia \\ E-mail: afida@upm.edu.my
}

Received: 08-07-2014

Accepted: 18-08-2014

Published: 01-01-2015

doi:10.7575/aiac.ijalel.v.4n.1p.14

URL: http://dx.doi.org/10.7575/aiac.ijalel.v.4n.1p.14

\begin{abstract}
Management foreword is an unedited qualitative section of Corporate Annual Reports (CARs). It is also considered as the most widely read section of CARs which may reveal the financial condition of the company. So far, only few language studies have embarked on analysis of this section and they have mainly focused on the genre content of management foreword rather than its genre structure. Nevertheless, the few genre studies conducted had several shortcomings in the model proposed. Besides, none of the previously move analysis studies on management foreword have considered corpus analysis tools in their procedure of analysis. Accordingly, the present study is aimed to bridge the gap in previous studies by describing the genre structure of management forewords. To that aim, a qualitative genre analysis study was conducted on 64 samples of management forewords of Asian companies using AntConc software. The analysis revealed six moves and nineteen move-strategy combinations. Most of the identified moves and strategies were also identified in previous move analysis studies on management forewords and other types of business reports and hence verified. The proposed move analysis model defined move boundaries and provided the most frequent words and verbs that represent each move. Additionally, the proposed moves consist of predictable strategies which are bound to their moves and do not appear within the boundary of more than one move. The findings of the present study could be useful for ESP practitioners as teaching material and raise awareness among business ESP students about the genre conventions of this genre.
\end{abstract}

Keywords: management foreword; move analysis; genre analysis

\section{Introduction}

Management foreword (MF) which is also called letter to shareholders is one of the narrative sections of corporate annual reports (CARs). This section is written in the format of a letter to shareholders/public. However, they are written in laymen's term and are not audited as they are accompanied by other sections of CARs which are audited; such as auditors' report (Bhatia, 2004; 2010; Cho \& Yoon, 2013; De Groot, 2008; Garzone, 2004; Plung \& Montgomery 2004). The importance of management foreword as a subject for genre analysis studies comes from several sources. First, they usually function as the introductory section of CARs. In addition, according to Plung and Montgomery (2004), a survey was conducted by Security and Exchange Commission (SEC) which revealed that management foreword is the most widely read section of CARs and most of the readers go through this section first in search of information as it contains a report of the company's past financial and non-financial accomplishments plus future plans (Conaway \& Wardrope, 2010; Crombie \& Samujh, 1999; De Groot, Korzilius, Ickerson \& Gerritsen, 2006; De Groot, 2008; Hyland, 1998; Jamson, 2000; Kohut \& Segars, 1992; Thomas, 1997). Most importantly, the credibility of annual reports depends on a truthful management foreword which tells the story as it is, accepts the responsibilities for losses instead of denying it or attributing it to outside factors, and reports major changes in the company which influences the profit making of the company. Finally, management foreword has an actual message writer. In other words, its writer is introduced to the readers through his/her picture, name and signature. However, that is not the case with other sections of annual reports. Accordingly, presenting the public with an efficient management foreword could be an opportunity for any company to communicate its performance and gain the trust of the members of this particular discourse community (Plung \& Montgomery, 2004).

\section{Literature Review}

Language studies on management foreword as a genre is fairly limited. These studies could be divided into three categories.

The first are studies conducted on content analysis and theme of good news and bad news (Clatworthy \& Jones, 2006; 
Conaway \& Wardrope, 2010; Crombie \& Samujh, 1999; De Groot, Korzilius, Nickerson \& Gerritsen, 2006; Jamson, 2000; Kohut \& Segars, 1992; Rogers, 2000; Thomas, 1997; Smith \& Taffler, 2000). These studies found that companies resort to different strategies to reveal bad news or losses e.g. focusing on future achievements, applying passive construction, process verbs and non-human agents or inanimate nominal group or they use multiple narrators and tend to be less informative. Another important finding was that bad news could be used strategically to convey the message that the managers are experts and can handle difficult situations. It is also possible to distinguish high performing firms from low performing ones only through analyzing the themes, keywords and linguistic features that appear in their management foreword. In short, language used in a management foreword could be as informative as quantitative sections of annual reports like balance sheet (Cho \& Yoon, 2013). In addition, the analysis on management foreword samples revealed that there exist significant cross-cultural differences between management forewords coming from different corporate cultures with regard to stylistic and thematic preferences.

The second category of studies involves linguistic features and metadiscoursal resources (De Groot, 2008; Garzone, 2004; 2005; Hyland, 1998). The findings of these studies confirmed that there exist both cross-cultural and cross-textual variation in the use of linguistic and metadiscoursal features. It was also discovered that the communicative purpose of the text could influence the choice of metadiscoursal features and some of these features are prominent in these texts, like the use of personal self-mention, and connectives.

The third category involves genre analysis studies. Studies that have considered the macrostructure of management foreword during the past decade are limited to the studies conducted by Nickerson and De Groot (2005), and De Groot (2008). Nickerson and De Groot (2005) studied chairman and CEO's statements from U.K and Netherlands and proposed five move patterns and 12 strategies that were listed separately. In conclusion, they stated that the communicative purpose of management foreword was to gain the confidence and trust of the readers. De Groot (2008) also considered the sub-genre of management foreword. The analysis revealed 10 moves and 20 strategies that were also listed separately. Both studies were comparative studies and identified statistically significant cross-cultural variations in the use of two strategies, and one move. However, the existing models seem inadequate for analysis of new samples. First, they did not clearly define their move boundaries and provided no textual clues for move identifications. Second, the strategies identified by them were not bound to a particular move. To put it differently, strategies were not constituents of a specific move and could appear within the boundary of more than one move. In addition, the analysis was apparently done manually and no corpus analysis tool was mentioned for analysis (Mobasher, Afida, Ain Nadzimah $\&$ Chan, 2013).

The aim of this research project has therefore been to compensate for the shortcomings of previous genre analysis studies on management foreword by proposing a move analysis model where each move has its own specific strategies. For the analysis, a corpus analysis tool called Antconc 3.3.5w (Laurence, 2012) was used. The purpose of the study was to identify the recurrent structural patterns (moves) preferred by the members of this discourse community and identify constituents within the moves as strategies through a qualitative analysis of 64 samples of management foreword; and to identify the most frequent words and verbs that represent each move. In other words, the present article aims at proposing a new move analysis model for management forewords of corporate annual reports. The analysis is grounded on the genre theory, following the ESP tradition. It is based on the notion that genres are recurring communicative events that occur in patterns which are recognized and followed by the members of its discourse community (Swales, 1990); and the fact that the constituents of the patterns do not always appear in a fixed sequence (Bhatia, 1993). This research seeks to address the following questions:

1. What are the moves that appear within the management forewords produced by Asian financial stock exchange companies?

2. What are the strategies that appear within identified moves?

3. What are the most frequent words that represent each move?

4. How are the identified moves distributed throughout the analyzed samples?

\section{Method}

The present study followed the descriptive analytic approach (Glaser \& Strauss, 1967) to propose a move analysis model for management forewords. The analysis encompassed a pilot study which is elaborated in one of the following sub-sections. The procedure of the analysis is visually presented in figure 1 at the end of this section.

\subsection{Corpus of the Study}

A corpus of 64 samples of management foreword, consisting of 73,862 words was created. The samples were obtained from two sources: 31 from the financial sector of Kuwait's main market stock exchange, and 33 from financial sector of Bursa Malaysia's main market. The uneven number of the samples is due to the fact that the study was trying to analyze as many samples as possible. The reason for collecting data from two different sources was to make sure that the identified moves are not idiosyncrasies of a particular corporate culture and would appear in samples from different sources. The management foreword samples were extracted from the annual reports of companies listed in the financial sector and as the original text was in pdf format they were converted to word document for analysis purposes. Data collection was done from February till March 2012 and the most recent CARs from each company website were downloaded. However, not all the companies published their 2012 annual report on their website during data collection. Consequently, a time range was decided for sample collection. As some of the companies' most recent annual report 
were published online since 2007 , the time range for samples was decided to be between 2007 to 2012 . The sampling in the present study is considered 'purposive sampling' because the sample texts were chosen from specific industries and time range (Ary, Jacobs \& Sorenson, 2010).

\subsection{The Analytical Approach and Procedure of the Study}

The analysis was conducted using qualitative discourse analysis techniques to analyze the corpus of management forewords. The texts of the 64 samples were carefully read several times to identify the macrostructure in terms of the recurring structural moves and the move constituents as strategies. Here, it needs to be reminded that genre analysis in the present study was conducted based on the definition of genre as 'a social action that has specific communicative purposes which is mutually understood among the members of that discourse community' (De Groot, 2008). In this definition, moves function as the building blocks of the genre (Salami Nodoushan \& Montazeran, 2012). Each move might consist of several sentences that realize the communicative purposes of a genre. They are "semantic and functional units" (Nwogu, 1997) that have identifiable communicative purposes which are coherently related to the communicative purpose of their genre. Move analysis means finding the discriminative, recurrent regularities in a specific text type. (Ding, 2007; Connor, Davis, \& De Rycker, 1995; Holmes, 1997; Nwogu, 1991; 1997; Bhatia, 1993; Bhatia, 2004; Flowerdew \& Wan, 2010). However, moves are general ideas or functions that are composed of several tactics with coherent communicative purposes which are called 'move constituents'. To find a move, a genre analyst first needs to find the move constituents; because these constituents form the moves. Move constituents are called steps or strategies. The difference between step and strategy is that steps have a fixed sequence, but strategies do not (Bhatia, 1993; Swales 1990).

The criteria for move identification in the present study were mainly functional; that is the texts were analyzed based on the communicative purpose of the management forewords mentioned in the literature (Bhatia, 2004; 2010; De Groot, 2008; Nickerson \& De Groot, 2005; Plung \& Montgomery, 2004). Another point that should be reminded here is that the constituents within moves were categorized as strategies and not steps; because these constituents tended to be irregular which is the characteristics of strategies (Bhatia, 1993; De Groot, 2008; Nickerson \& De Groot, 2005).

What needs to be emphasized here is that the researcher conducted several interviews with an expert informant from a corporation to better understand the discourse conventions of producing management forewords. As he was one of the people involved in producing management foreword text, the interviews helped in clarifying the research findings and understanding the discourse conventions of the text through the eyes of an expert insider from the particular discourse community.

\subsection{Preliminary Analysis}

The analysis started with a literature review of studies on management forewords and move analysis models proposed for this genre (De Groot, 2008; Nickerson \& De Groot, 2005) and also a careful study of a few samples of management forewords from Kuwait and Malaysia. However, previously proposed models have not dealt with several issues and were not applicable for the present study for several reasons. First, the studies did not elaborate on their criteria of move identification. They described every move in one sentence only. Second, none of the moves had been supported by literature from similar business studies. Third, no key word or most frequent word representing the moves was provided. Fourth, they did not provide any move constituents. In fact, they provided a list of moves and a list of strategies separately. In other words, these strategies were not bound to a particular move (Mobasher, et al., 2013). For example, in De Groot's (2008) model there is a move named 'speculating on future' and two strategies 'future prospects' and 'future objective'. These strategies were also free to appear within the move 'financial performance of the company' or 'communicating corporate strategy' or any other move in her model which does not seem to be accurate as each move has a specific communicative purpose and the communicative purpose of move constituents needs to match the communicative purpose of the move; that is the communicative purpose of a move is supposed to be the sum of the communicative purposes of its constituents (Bhatia, 1993; Schroder,1991; Swales, 1990; 2004). Finally, the proposed models did not define the communicative purposes of management forewords. In short, the models were not clearly presented. Considering the shortcomings of the previously proposed move analysis models, the researchers had to start from scratch and propose their own moves for management foreword. So, a pilot study of 6 samples of management foreword was conducted. The analysis resulted in an unsatisfactory model with many moves. The reason was the small number of the samples and the nature of business texts. According to Bhatia (1993), De Groot (2008), and Nickerson and De Groot (2005) business texts do not tend to be as organized as academic texts, consequently, the move boundaries could not be decided clearly.

\subsection{Modification of the Preliminary Move Model}

To modify the proposed moves, all of the obtained samples were read carefully. Then, a thorough literature review of move definition and boundaries was conducted (e.g. Ding, 2007; Connor, Davis, \& De Rycker, 1995; Henry and Roseberry, 1996; 1997; 1998; Holmes, 1997; Nwogu, 1991; 1997; Bhatia, 1993; Bhatia, 2004; Flowerdew \& Wan, 2010; Swales, 1990) which was followed by a literature review of the communicative purposes of management forewords (Bursa Malaysia, 2013; Garzone, 2004; Plung \& Montgomery, 2004). Afterwards, some modifications were conducted on the moves and they were reduced. The new model was used to analyze all of the obtained samples. However, some of the moves consisted of too many strategies. For example, the move 'financial performance' had as many as 15 strategies; like 'reporting income, 'reporting capital', 'reporting losses, etc. Another problem with these strategies was that the frequency of some of those strategies were as low as 5 in all 64 samples. There was no instance 
of a move in the literature that had so many strategies with such low frequency. Due to this, consultation was done with the inter-coders and an expert informant from a corporation. It was agreed that the strategies needed some modifications. With reference to the literature (Conaway \& Wardrope, 2010; De Groot, Korzilius, Ickerson \& Gerritsen, 2006; De Groot, 2008) it turned out that the items which were identified as strategies (e.g. income, reporting capital, etc.) were actually themes that might appear within a strategy. Considering the literature, similar themes were merged into strategies. For example, items like 'income', 'loss', 'profit', 'dividend' are all providing details of financial performance (De Groot et al., 2006; De Groot, 2008). Thereupon, these themes were merged under a strategy called 'reporting on details of financial performance'.

Merging themes into strategies resulted in new strategies. Consequently, the new strategies that had similar purpose were grouped into a move. For example, 'informing the readers of the details of company's non-financial performance' and 'flaunting company credibility' were grouped into 'reporting company's operational performance and achievements' move. The procedure of proposing the present model is visually presented in figure 1 .

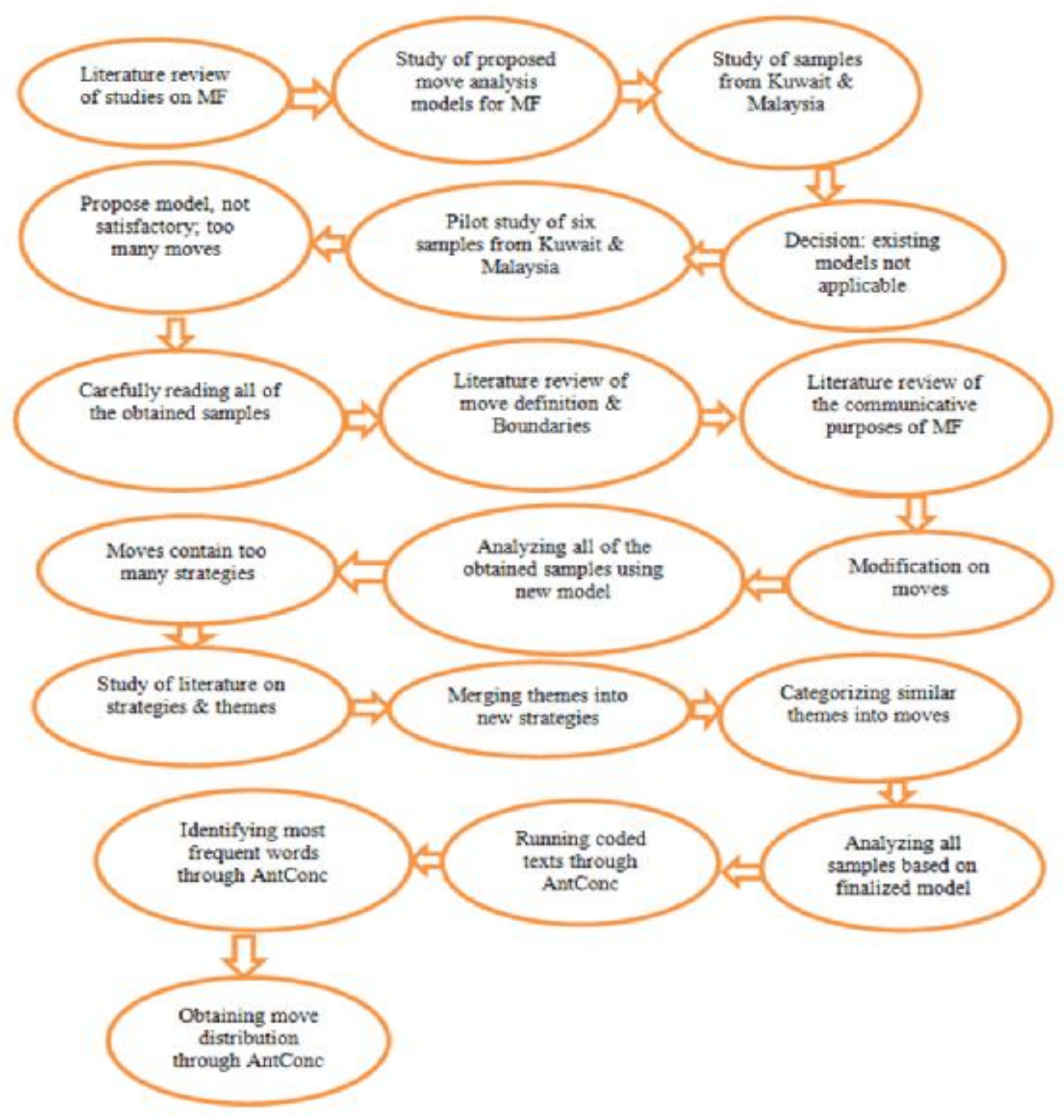

Figure 1. Visual presentation of the procedure of proposing the present move model

\subsection{Move Analysis based on the Proposed Model}

When all move-strategy combinations were identified, they were coded in all 64 samples in word document format. For accuracy, all samples were coded several times for moves and move-strategy combinations. Then the word document files were converted into txt files and run through Antconc 3.3.5 (Laurence, 2012) to find the move distribution. Subsequently, each move from all samples was extracted and saved in a separate word document. These word document files were converted into txt files and run through Antconc 3.3.5w (Laurence, 2012) again to find the most frequent words and verbs that represent each move.

\subsection{Inter-Coder Reliability}

The reliability of analysis for the present study was considered through inter-coder reliability. To ensure this, two Ph.D. 
candidates were trained about the moves and move-strategy combinations. Discussions were made several times in finalizing the move model. The coders were given 32 samples out of 64 . They were asked to code the texts 'using the coding labels identified by the researcher'; that is the definition of the moves and move-strategy combinations provided by the researcher (Ary, Jacobs \& Sorensen, 2010, p. 503). The results were obtained and the inter-coder reliability showed $89 \%$ of agreement (Freelon, 2010). Both Bhatia (1993, p. 93) and Upton (2002) confirm that no matter how clearly moves might be defined, sometimes 'there can still be cases which will pose problems and escape identification or clear discrimination, however fine a net one may use. After all, we are dealing with the rationale underlying linguistic behavior rather than its surface form'.

\section{Results}

\subsection{The Macrostructure of the Management Foreword}

The analysis of management foreword samples revealed six structural moves that could be further articulated into strategies, resulting in nineteen move-strategy combinations. This macrostructure is schematically outlined in Table 1 which answers the first and second research questions. The most frequent words (the third research question) that represent each move are provided in each move's discussion.

Table 1. Moves and move-strategy combinations identified in management foreword

\begin{tabular}{|c|c|}
\hline Move & Strategy \\
\hline Move1.OPN: opening the report & $\begin{array}{l}\text { Strategy 1: salutation } \\
\text { Strategy 2: presenting the report } \\
\text { Strategy 3: presenting topics of discussion }\end{array}$ \\
\hline $\begin{array}{l}\text { Move2.ECEN: reporting economic environment of the } \\
\text { market }\end{array}$ & $\begin{array}{l}\text { Strategy 1: describing market condition } \\
\text { Strategy 2: reporting measures taken to influence market } \\
\text { condition } \\
\text { Strategy 3: presenting outcome of measures taken } \\
\text { Strategy 4: reporting the company condition/status with } \\
\text { regard to market condition }\end{array}$ \\
\hline Move3.FP: reporting company's financial performance & $\begin{array}{l}\text { Strategy 1: taking pride about financial performance } \\
\text { Strategy 2: providing details of company's financial results } \\
\text { Strategy 3: reporting financial strategy or measures }\end{array}$ \\
\hline $\begin{array}{l}\text { Move4.OP: reporting company's operational } \\
\text { performance and achievement }\end{array}$ & $\begin{array}{l}\text { Strategy 1: informing readers of the details of company's } \\
\text { non-financial conducts } \\
\text { Strategy 2: flaunting company credibility }\end{array}$ \\
\hline Move5.FTR: previewing future & $\begin{array}{l}\text { Strategy 1: reporting future plans and strategies } \\
\text { Strategy 2: expressing expectations for future }\end{array}$ \\
\hline Move6.CLS: concluding the letter & $\begin{array}{l}\text { Strategy 1: giving polite words } \\
\text { Strategy 2: giving the name of the message sender } \\
\text { Strategy 3: clarifying the professional role of message sender } \\
\text { Strategy 4: providing the date of the report } \\
\text { Strategy 5: providing the signature of the message sender }\end{array}$ \\
\hline
\end{tabular}

Move one - Opening the Report

The first point that was noticed in management foreword samples was that most of the samples were written in the format of a letter to shareholders. So, they followed the 'conventional indicators' that usually appear in these types of genres. They started with formally addressing the shareholders and formally presenting the report (Bhatia, 2004, p. 16; Nickerson \& De Groot, 2005). Interestingly, in their formal opening they addressed the readers and presented the annual report instead of the management foreword. Besides, the topics of discussion throughout the annual report were occasionally presented. The fact that they presented the annual report rather than the management foreword might indicate that the management foreword functions as the introduction section of annual reports.

Since a formal opening is a function that appears in letters, it was considered as the first move of the management foreword. M1.OPN appears only once throughout the text and at the very beginning of the management foreword and consisted of three smaller functions, realized as strategies. It was named formal opening of the report and not formal opening of the letter because it presents the annual report and is not limited to management foreword only which could be considered as a case of intertexuality as it is connecting the sub-genre of management foreword to other sub-genres within the annual report (Bhatia, 2004; 2010). The naming of the strategies was based on their function. The most frequent words that appear within this move are 'annual report', 'company', 'shareholder ', 'behalf', 'pleasure'. The most frequent verb used in this move is 'is'.

M1. OPNs1 (where M refers to Move, s refers to strategy and henceforth) is a salutation to the shareholders which was also identified by De Groot (2008). An example of M1.OPNs1 would be 'Honorable shareholders'. 
M1. OPNs2 formally 'presents the report', with phrases such as, 'I am pleased/ we are pleased'. It also states to which year the report belongs to. This strategy was also identified by De Groot (2008). An example of M1.OPNs2 would be 'On behalf of the board of directors, it is my pleasure to present the annual report of the company and its subsidiaries for the financial year ended 31 December 2010'.

M1. OPNs3 presents topics of discussion in the CAR, seemingly with the purpose of inviting and encouraging the shareholders to read the other sections of annual reports to get more detailed information. An example of M1.OPNs3 would be 'The report illustrates the Company's performance during the year 2010, and also includes the financial statements and the auditors' report for the fiscal year ending on 31st of December 2010'.

\section{Move 2 - Market Environment}

The purpose of this move is to indicate that the performance of the company was carried under specific business circumstances (Bhatia, 2004). It mainly discusses challenges that exist in the company's context of operations and whether the government(s) has tried to manipulate the market condition. It might also report the results of these manipulations. The most frequent words of M2.ECEN are 'crisis', 'global', 'market', 'regional', 'prices' and the most frequent verbs of this move are 'is', 'were', and 'have'. Some sub-headings that might appear for M2.ECEN are 'market overview', 'overall business environment', 'economic and business environment review', and 'operating environment'.

M2. ECENs1 describes the economic condition and it might cover the global, regional and local market condition or be limited to describing the local market condition. De Groot (2008) also introduced a similar strategy. An example of M2.ECENs1 would be 'As you are aware, the world economy is witnessing a challenging survival of overcoming the repercussions of the economic downturn which started by the end of year 2008. Following the 2008 financial meltdown and ensuing global economic crisis, the year 2009 witnessed unprecedented global economic and financial transformation. The crisis has left adverse impact on the asset prices in all sectors of the economy'. M2.ECENs2 involves measures taken to influence market conditions, which usually involves the actions taken by the government to manipulate the market conditions. An example of M2.ECENs2 would be 'Concurrent with the market insights, just before the end of the first quarter of 2010, the Prime Minister announced the RM67 billion Stimulus Package with the purpose to be the catalyst for the country to overcome the impact of global financial crisis of 2008 and hence to find its way out of the recession'.

M2.ECENs3 is the 'outcomes of the measures taken' which explains what has happened in the market condition as a result of government's interference. An example of M2.ECENs3 would be 'Subsequent to each announcement, market activities picked up steadily as investors' confidence rose and sentiments turned positive. Towards the end of second quarter, market was buoyed with high anticipations that Malaysian economy would perform better than expected'. M2.ECENs4 which is 'the company condition/status with regard to market condition' only reports company's situation in the particular year in general terms. An example of M2.ECENs4 would be 'we were able to achieve growth in operations and results despite the challenging business environment during the year under review. Nevertheless, the economic slowdown affected certain segments of the Company's customer base and resulted in reduced annual growth rate'.

However, the difficulty with this move is that its last strategy 'company condition/status with regard to market condition' might be confused with the first strategy of the move financial performance (M3.FP) which is 'taking pride in financial performance'; because they are usually both positive statements about company performance. To solve this issue, the analyst needs to consider the previous and succeeding sentences. If those sentences mention about financial performance or there is a subheading referring to financial performance then the statement is a case of M3.FPs1. However, if the preceding and following sentences are setting the market scene and discusses the challenges, then it is a case of M2.ECENs4. This move might appear several times throughout the text or might not appear in a text; and it is named 'reporting economic environment of the company' based on its function and subheadings like 'overview on economic environment' plus similar terms used in literature (Bhatia, 2004; De Groot, 2008).

\section{Past Year Performance as Moves}

According to the literature, the main function of management foreword is to report on past performance and give a preview of future plans (Bhatia, 2004; De Groot, 2008; Garzone, 2004; Kloprchenko, Eklund, Karisson, Vanharanta \& Visa, 2004; Li 2010; Nickerson \& De Groot, 2005; Plung \& Montgomery, 2004; Ripken, 2005). According to the findings of the present study and the literature, past performance could be divided into two functions: reporting on financial performance and reporting on operational/non-financial performance (Bursa Malaysia Security Berhad, 2013; De Groot, 2008; Nickerson \& De Groot, 2005). These two functions could be considered as 'complimentary moves'; meaning that they complete each other, but they can stand alone. If they co-exist, the management foreword would be more informative in comparison to when one of them is missing. SEC requirements (e.g. Bursa Malaysia Security Berhad, 2013) and literature (Bhatia, 2004; Plung \& Montgomery, 2004) insist on providing a report of past performance; however it does not specify whether it should include both financial and operational performances or if one would suffice. The justification for naming these two functions as 'operational and financial performance' comes from the subheadings that existed in the samples analyzed like 'operational review' and 'financial results' and the terms used in the literature (Camiciottoli, 2010: Cho \& Yoon, 2013; De Groot, 2008; Nickerson \& De Groot, 2005).

\section{Move 3 - Financial Performance}

The most prominent function present in management forewords seemed to be financial performance of the company; 
because it appeared in all of the samples and its prominent feature was the figures reported. It is that part of the text which provides the amount of income, profit, losses, loans and etc. These results pertain to the financial results of both the company and its subsidiaries. This move was also identified by De Groot (2008) and Nickerson and De Groot (2005) in management foreword samples from UK and Netherlands and in the text of earning calls by Camiciottoli (2010) and Cho and Yoon (2013). The most frequent words that appear within M3.FP are 'Million', 'company', 'year', 'assets', 'investment', 'loss(es)', 'share', 'results', 'income', 'equity', 'profit', 'value', and the most frequent verbs that appear within this move are 'Compare', 'were', and 'amounted'. Occasionally there are subtitles like (overview of) 'financial results'.

M3.FPs1 is 'taking pride about financial performance'. Occasionally when companies report good results they take pride in it and announce it confidently. An example of M3.FPs1 would be 'I am delighted to report that your Group has once again registered a credible performance for the financial year ended 31 December 2010'. M3.FPs2 is 'providing details of company's financial results' including subsidiaries. It is the main strategy of the M3.FP. Its function is to provide details of financial conducts for the main company and its subsidiaries which was also reported by De Groot (2008). An example of M3.FPs2 would be 'Net profit reached RM.49 million, while total assets reached RM259 million, representing another milestone in 2010 continued operations...' M3.FPs3 reports on 'financial measures/strategies' and its purpose is to provide insight into what the company have done in gaining more profits. It is usually concerned about investment plans which were also identified by De Groot (2008) and Nickerson and De Groot (2005). An example of M3.FPs3 would be 'On the investment arena, the Company continued its prudent policy in leveraging the investment opportunities under the circumstances of continuing effects of the financial crisis, and the instability of the financial markets. The company's activity in this regard was limited to entering into a number of short-term, highly liquid investments, in addition to monitoring and nurturing the existing investments'.

Move 4 -Operational Performance

The second part of past performance encompasses reports of company's non-financial conducts called 'operational performance'. It is what the company has done or achieved during the past year which does not immediately influence financial gains or losses of the company, but eventually might result in financial gains; like opening a new branch, merging some subsidiaries, change in company management, research and studies on the market. These are the details of operational performance. However, some other information about past actions were presented which were not about company's performance. Those pieces of information were about achievements or even acts of corporate social responsibility (CSR) rather than on performance. Further analysis and studies revealed that company achievements and CSRs are in fact for the purpose of creating a positive image for the company which leads to influencing the company's financial performance indirectly (Bhatia, 2010; Gary \& Balmer, 1998; Schmitt, Simonson \& Marcus1995; Spyropoulo, Skarmeas \& Katsikeas, 2010; Stanwick \& Stanwick, 1998). Accordingly, company achievements such as awards won and company social responsibilities were categorized as 'flaunting company credibility' as a strategy of 'company's operational performance'.

The most frequent words that appeared within this move are 'Company', 'our', 'project', 'research', 'business', 'service', 'group', 'operation' and the most frequent verbs that are used within this move are 'is', 'was', 'has', 'have', 'are'. Finally, the subheadings that might occasionally appear and indicate that the text is about company's operational performance are 'operational review', 'corporate developments', 'corporate social responsibility', 'awards', 'review of operations', and 'performance overview'. This move consists of two strategies. M4.OPs1 is 'providing details of company's non-financial conducts'. It informs the reader about the details of the tasks that the company and its divisions or subsidiaries have undertaken in the previous year. It covers whatever the company has done during the past year which does not directly result in financial gains. It might include information on opening new branches, ending of a project or the beginning of a new one, or activities and decisions e.g. change in management, seminars held or attended and so on. This strategy was also reported by De Groot (2008). An example of M4.OPs1 would be 'Our shareholders base has increased to more than 9,500 shareholders currently from over 8,800 a year earlier'... 'In addition to the aforesaid and in continuation of the series of operational successes, FUCOM Supermarkets Company (subsidiary company) has inaugurated its first supermarket under the name of Geant at 360 Mall'. M4.OPs2 is 'flaunting company credibility'. It seems that companies would like to win readers' approval through persuading them about the company's credibility. This is done by flaunting their credibility through reporting on their CSR and HR activities, the awards won, the certificates and ranking achieved. De Groot (2008, p.143) also identified two similar strategies and called them 'involvement in HRM/CSR' and 'focus on strength and credibility'. Nevertheless, both are considered as one strategy in the present study as they both contribute to the credibility of the company and picturing a positive image of the company. To put it differently, they have mutual function. An example of M4.OPs2 would be 'During the year, the Group's CSR initiatives emphasized employee and Agency participation as well as contribution in kind that helped to improve the quality of life for underprivileged children, old folks, mentally disabled children or the physically handicapped. The Group started the year by funding the establishment of a bakery at Sekolah Sinar Harapan, a welfare school in Bukit Mertajam for mentally disabled children...' yet another example would be 'It is worth mentioning that we won the "Leading Middle Eastern Overseas Developer" award at the 2008 World Travel Awards'.

\section{Move 5 - Previewing Future}

What remains from the main purpose of writing management foreword is 'previewing future': a function that appeared 
in most of the samples. It was also a prominent function due to the subheadings (e.g. prospects) indicating this function. Moreover, the verb tense for this move tended to be mainly future. This function is called forward looking statements (FLS) in the literature (e.g. Bhatia, 2004; Li 2010). Companies are advised by security exchange commissions (SEC) to provide forward looking statements about their plans and their expectations for the future of their industry in the market. These statements are in positive tone expressing company's best hopes for future. These hopes could be limited to the hopes and expectations of the company or it could go beyond the company and include hopes for improvements on local, regional or global economy (Bhatia, 2004; De Groot, 2008; Kloprchenko et al., 2004; Li 2010; Nickerson \& De Groot, 2005; Ripken, 2005).

Through this move, the management informs the public about the company's future plans, what could be expected to happen and in what economic environment the company might be operating in the future. the companies take caution in their forward looking statements as disclosing wrong information or predictions that do not materialize would influence company's reputation and sometimes lead to legal actions taken against companies for misleading the public (Bhatia, 2004; Kloprchenko et al., 2004; Li 2010; Ripken, 2005). As investors are interested to read about the company's future to make informed judgments for investing purposes, this move might indirectly attract potential investors through the use of a positive tone on the profitability of the company.

Although the verb tense for this move tends to be future, M5.FTR is not about future tense only and not all sentences that are in future tense are necessarily considered as M5.FTR. in order to be considered as move FTR, the sentences need to be about the company's plans and hopes for the future. for example in the sentence 'meanwhile, the group/ecm Libra foundation continued to support worthy infrastructure needs by contributing to the new hostel for Monfort boys in Shah Alam town, a project that will enable 120 children to be given alternative education', the use of will does not indicate M5.FTR as the sentence is not about company's future plans. It simply reports on the company's actions at present that would influence the future of some children. Interestingly, the actions taken in the example sentence are related to some CSR activity. Considering that CSR activities of the company belong to the category of the company's operational performance; then this sentence is from M4.OP 'reporting on company's operational performance'. De Groot (2008, p. 140) also identified this move and called it 'speculating on future performance'. Occasionally there are subtitles like 'prospects', 'future plans', 'outlook and prospects', 'the way forward', 'business outlook and prospects', 'prospects for ...' which might help in finding move FTR. The most frequent words that might appear within this move are 'investments', 'opportunities', 'clients', 'growth', 'coming', 'expected' and the most frequent verbs are 'anticipate,' 'plan', 'hope', 'will be', which were also reported by $\mathrm{Li}$ (2010). In the present study, discussion of future plans is named as 'previewing future' because companies do not provide exact details about future plans and only generally mention what the company plans or hopes to do for future and also how it predicts the future would be. M5. FTRs1 is about 'reporting future plans and strategies' of the company. The sentences do not always disclose exact information about what they plan to do in the future (Kloprchenko et al., 2004; Ripken, 2005). An example of M5.FTRs1 is '.. will continue to identify and explore more direct investment opportunities in vital sectors such as industry, health and education. We will also continue supporting and promoting the company's social responsibility program'.

M5.FTRs2 is 'about expectations for future'. For this strategy, companies tend to express their hope and expectations for the future of the company or even for future of market condition at local, regional or global level. The expectations are usually expressed in a positive tone ( $\mathrm{Li}, 2010)$. an example of M5.FTRs2 would be 'the Malaysian economy is expected to further improve in 2010 , with a GDP of $7.0 \%$ to $8.0 \%$ following the strong performance in the first quarter of 2010 with $10.1 \%$ growth, underpinned by the government's stimulus spending, improved external and domestic demands, access to credit and better consumer confidence'.

Move 6 - Concluding the Letter

As mentioned earlier, the management foreword also has a formal closing (Bhatia, 2004; Nickerson \& De Groot, 2005). Unlike the formal opening, the formal closing concludes the management foreword only. It has a double function; first it separates the management foreword from other sections of annual reports and second, it somehow authenticates the information disclosed in the letter through confirming who the message writer is. The professional role of the message writer is also provided, so that the readers know who is responsible for what was disclosed. Revealing the identity of the message writer might also be an indication that information disclosed is reliable; because it is disclosed by a member of the management board. This function is considered as the last move and is called concluding the letter and not the report; because it closes the management foreword. The most frequent words that appear within move CLS are 'chairman', 'director', 'board' and 'signature'. Given that this move does not comprise of sentences, no verbs were used for this move.

M6.CLSs1 provides a polite word like 'regards' which has also been identified by De Groot (2008). An example of M6.CLSs1 would be 'Thank you all'.

M6.CLSs2 introduces to the writer through his/her name. An example of M6.CLSs2 would be 'Bader Naser alSubaiee ,

M6.CLSs3 provides the 'professional role' of the message sender like 'chairman'. An example of M6.CLSs3 would be 'Chairman'.

M6.CLSs4 provides the date that the report was written. An example of M6.CLSs4 would be '31 December 2010'. M6.CLSs5 is the 'signature' of the message writer. An example of M6.CLSs5 would be 


\subsection{Distribution of the Moves and Discussion}

After identifying moves and move-strategy combinations in the analyzed samples, the samples were run through AntConc 3.3.5w (Laurence, 2012) to find the distribution of the moves and answer the fourth research question. The results are provided in Table 2 and 3.

Table 2. Distribution of moves in management foreword of Kuwaiti companies

\begin{tabular}{|c|c|c|c|c|c|c|}
\hline Company & OPN & ECEN & FP & OP & FTR & CLS \\
\hline MF1 & $\sqrt{ }$ & $\sqrt{ }$ & $\sqrt{ }$ & $\sqrt{ }$ & $\sqrt{ }$ & $\sqrt{ }$ \\
\hline MF2 & - & $\sqrt{ }$ & $\sqrt{ }$ & $\sqrt{ }$ & $\sqrt{ }$ & $\sqrt{ }$ \\
\hline MF3 & $\sqrt{ }$ & $\sqrt{ }$ & $\sqrt{ }$ & $\sqrt{ }$ & - & $\sqrt{ }$ \\
\hline MF4 & $\sqrt{ }$ & $\sqrt{ }$ & $\sqrt{ }$ & $\sqrt{ }$ & $\sqrt{ }$ & $\sqrt{ }$ \\
\hline MF5 & $\sqrt{ }$ & $\sqrt{ }$ & $\sqrt{ }$ & $\sqrt{ }$ & $\sqrt{ }$ & $\sqrt{ }$ \\
\hline MF6 & $\sqrt{ }$ & $\sqrt{ }$ & $\sqrt{ }$ & $\sqrt{ }$ & $\sqrt{ }$ & $\sqrt{ }$ \\
\hline MF7 & $\sqrt{ }$ & $\sqrt{ }$ & $\sqrt{ }$ & $\sqrt{ }$ & $\sqrt{ }$ & $\sqrt{ }$ \\
\hline MF8 & - & $\sqrt{ }$ & $\sqrt{ }$ & - & $\sqrt{ }$ & $\sqrt{ }$ \\
\hline MF9 & $\sqrt{ }$ & - & $\sqrt{ }$ & $\sqrt{ }$ & $\sqrt{ }$ & $\sqrt{ }$ \\
\hline MF10 & $\sqrt{ }$ & $\sqrt{ }$ & $\sqrt{ }$ & $\sqrt{ }$ & $\sqrt{ }$ & $\sqrt{ }$ \\
\hline MF11 & $\sqrt{ }$ & $\sqrt{ }$ & $\sqrt{ }$ & $\sqrt{ }$ & $\sqrt{ }$ & $\sqrt{ }$ \\
\hline MF12 & $\sqrt{ }$ & $\sqrt{ }$ & $\sqrt{ }$ & - & $\sqrt{ }$ & $\sqrt{ }$ \\
\hline MF13 & - & $\sqrt{ }$ & $\sqrt{ }$ & $\sqrt{ }$ & $\sqrt{ }$ & $\sqrt{ }$ \\
\hline MF14 & $\sqrt{ }$ & $\sqrt{ }$ & $\sqrt{ }$ & $\sqrt{ }$ & $\sqrt{ }$ & $\sqrt{ }$ \\
\hline MF15 & $\sqrt{ }$ & $\sqrt{ }$ & $\sqrt{ }$ & $\sqrt{ }$ & $\sqrt{ }$ & $\sqrt{ }$ \\
\hline MF16 & - & $\sqrt{ }$ & $\sqrt{ }$ & $\sqrt{ }$ & $\sqrt{ }$ & $\sqrt{ }$ \\
\hline MF17 & $\sqrt{ }$ & $\sqrt{ }$ & $\sqrt{ }$ & - & $\sqrt{ }$ & $\sqrt{ }$ \\
\hline MF18 & $\sqrt{ }$ & - & $\sqrt{ }$ & $\sqrt{ }$ & $\sqrt{ }$ & $\sqrt{ }$ \\
\hline MF19 & $\sqrt{ }$ & $\sqrt{ }$ & $\sqrt{ }$ & $\sqrt{ }$ & $\sqrt{ }$ & $\sqrt{ }$ \\
\hline MF20 & $\sqrt{ }$ & $\sqrt{ }$ & $\sqrt{ }$ & $\sqrt{ }$ & $\sqrt{ }$ & $\sqrt{ }$ \\
\hline MF21 & $\sqrt{ }$ & $\sqrt{ }$ & $\sqrt{ }$ & - & $\sqrt{ }$ & $\sqrt{ }$ \\
\hline MF22 & $\sqrt{ }$ & $\sqrt{ }$ & $\sqrt{ }$ & $\sqrt{ }$ & $\sqrt{ }$ & $\sqrt{ }$ \\
\hline MF23 & $\sqrt{ }$ & $\sqrt{ }$ & $\sqrt{ }$ & $\sqrt{ }$ & $\sqrt{ }$ & $\sqrt{ }$ \\
\hline MF24 & $\sqrt{ }$ & $\sqrt{ }$ & $\sqrt{ }$ & $\sqrt{ }$ & $\sqrt{ }$ & $\sqrt{ }$ \\
\hline MF25 & $\sqrt{ }$ & $\sqrt{ }$ & $\sqrt{ }$ & $\sqrt{ }$ & $\sqrt{ }$ & $\sqrt{ }$ \\
\hline MF26 & $\sqrt{ }$ & $\sqrt{ }$ & $\sqrt{ }$ & $\sqrt{ }$ & $\sqrt{ }$ & $\sqrt{ }$ \\
\hline MF27 & - & $\sqrt{ }$ & $\sqrt{ }$ & $\sqrt{ }$ & $\sqrt{ }$ & $\sqrt{ }$ \\
\hline MF28 & $\sqrt{ }$ & $\sqrt{ }$ & $\sqrt{ }$ & $\sqrt{ }$ & - & $\sqrt{ }$ \\
\hline MF29 & $\sqrt{ }$ & $\sqrt{ }$ & $\sqrt{ }$ & $\sqrt{ }$ & $\sqrt{ }$ & $\sqrt{ }$ \\
\hline MF30 & $\sqrt{ }$ & $\sqrt{ }$ & $\sqrt{ }$ & $\sqrt{ }$ & $\sqrt{ }$ & $\sqrt{ }$ \\
\hline MF31 & $\sqrt{ }$ & $\sqrt{ }$ & $\sqrt{ }$ & $\sqrt{ }$ & $\sqrt{ }$ & $\sqrt{ }$ \\
\hline
\end{tabular}

Table 3. Distribution of moves in management foreword of Malaysian companies

\begin{tabular}{lcccccc}
\hline Company & OPN & ECEN & FP & OP & FTR & CLS \\
\hline MF1 & $\sqrt{ }$ & $\sqrt{ }$ & $\sqrt{ }$ & $\sqrt{ }$ & $\sqrt{ }$ & $\sqrt{ }$ \\
\hline MF2 & $\sqrt{ }$ & $\sqrt{ }$ & $\sqrt{ }$ & $\sqrt{ }$ & $\sqrt{ }$ & $\sqrt{ }$ \\
\hline MF3 & $\sqrt{ }$ & $\sqrt{ }$ & $\sqrt{ }$ & - & $\sqrt{ }$ & $\sqrt{ }$ \\
\hline MF4 & $\sqrt{ }$ & $\sqrt{ }$ & $\sqrt{ }$ & $\sqrt{ }$ & $\sqrt{ }$ & $\sqrt{ }$ \\
\hline MF5 & $\sqrt{ }$ & $\sqrt{ }$ & $\sqrt{ }$ & $\sqrt{ }$ & $\sqrt{ }$ & $\sqrt{ }$ \\
\hline MF6 & $\sqrt{ }$ & $\sqrt{ }$ & $\sqrt{ }$ & $\sqrt{ }$ & $\sqrt{ }$ & $\sqrt{ }$ \\
\hline MF7 & $\sqrt{ }$ & $\sqrt{ }$ & $\sqrt{ }$ & - & $\sqrt{ }$ & $\sqrt{ }$ \\
\hline MF8 & $\sqrt{ }$ & $\sqrt{ }$ & $\sqrt{ }$ & $\sqrt{ }$ & $\sqrt{ }$ & $\sqrt{ }$ \\
\hline MF9 & - & $\sqrt{ }$ & $\sqrt{ }$ & $\sqrt{ }$ & $\sqrt{ }$ & $\sqrt{ }$ \\
\hline MF10 & $\sqrt{ }$ & - & $\sqrt{ }$ & - & $\sqrt{ }$ & $\sqrt{ }$ \\
\hline MF11 & $\sqrt{ }$ & $\sqrt{ }$ & $\sqrt{ }$ & $\sqrt{ }$ & $\sqrt{ }$ & $\sqrt{ }$ \\
\hline MF12 & $\sqrt{ }$ & $\sqrt{ }$ & $\sqrt{ }$ & $\sqrt{ }$ & $\sqrt{ }$ & $\sqrt{ }$ \\
\hline MF12 & $\sqrt{ }$ & $\sqrt{ }$ & $\sqrt{ }$ & $\sqrt{ }$ & $\sqrt{ }$ & $\sqrt{ }$ \\
\hline MF14 & $\sqrt{ }$ & $\sqrt{ }$ & $\sqrt{ }$ & - & $\sqrt{ }$ & $\sqrt{ }$ \\
\hline MF15 & $\sqrt{ }$ & $\sqrt{ }$ & $\sqrt{ }$ & $\sqrt{ }$ & $\sqrt{ }$ & $\sqrt{ }$ \\
\hline MF16 & $\sqrt{ }$ & - & $\sqrt{ }$ & $\sqrt{ }$ & $\sqrt{ }$ & $\sqrt{ }$ \\
\hline MF17 & $\sqrt{ }$ & $\sqrt{ }$ & $\sqrt{ }$ & $\sqrt{ }$ & $\sqrt{ }$ & $\sqrt{ }$ \\
\hline MF18 & $\sqrt{ }$ & $\sqrt{ }$ & $\sqrt{ }$ & - & $\sqrt{ }$ & $\sqrt{ }$ \\
\hline MF19 & $\sqrt{ }$ & $\sqrt{ }$ & $\sqrt{ }$ & $\sqrt{ }$ & $\sqrt{ }$ & $\sqrt{ }$ \\
\hline
\end{tabular}




\begin{tabular}{lllllll} 
MF20 & $\sqrt{ }$ & $\sqrt{ }$ & $\sqrt{ }$ & $\sqrt{ }$ & $\sqrt{ }$ & $\sqrt{ }$ \\
\hline MF21 & $\sqrt{ }$ & $\sqrt{ }$ & $\sqrt{ }$ & - & $\sqrt{ }$ & $\sqrt{ }$ \\
\hline MF22 & $\sqrt{ }$ & $\sqrt{ }$ & $\sqrt{ }$ & $\sqrt{ }$ & $\sqrt{ }$ & $\sqrt{ }$ \\
\hline MF23 & $\sqrt{ }$ & $\sqrt{ }$ & $\sqrt{ }$ & $\sqrt{ }$ & $\sqrt{ }$ & - \\
\hline MF24 & $\sqrt{ }$ & $\sqrt{ }$ & $\sqrt{ }$ & - & - & $\sqrt{ }$ \\
\hline MF25 & $\sqrt{ }$ & - & $\sqrt{ }$ & $\sqrt{ }$ & $\sqrt{ }$ & $\sqrt{ }$ \\
\hline MF26 & - & $\sqrt{ }$ & $\sqrt{ }$ & $\sqrt{ }$ & $\sqrt{ }$ & $\sqrt{ }$ \\
\hline MF27 & $\sqrt{ }$ & $\sqrt{ }$ & $\sqrt{ }$ & - & $\sqrt{ }$ & $\sqrt{ }$ \\
\hline MF28 & $\sqrt{ }$ & $\sqrt{ }$ & $\sqrt{ }$ & $\sqrt{ }$ & $\sqrt{ }$ & $\sqrt{ }$ \\
\hline MF29 & $\sqrt{ }$ & $\sqrt{ }$ & $\sqrt{ }$ & $\sqrt{ }$ & $\sqrt{ }$ & $\sqrt{ }$ \\
\hline MF30 & $\sqrt{ }$ & $\sqrt{ }$ & $\sqrt{ }$ & $\sqrt{ }$ & - & $\sqrt{ }$ \\
\hline MF31 & $\sqrt{ }$ & $\sqrt{ }$ & $\sqrt{ }$ & - & $\sqrt{ }$ & $\sqrt{ }$ \\
\hline MF32 & $\sqrt{ }$ & $\sqrt{ }$ & $\sqrt{ }$ & $\sqrt{ }$ & $\sqrt{ }$ & $\sqrt{ }$ \\
\hline MF33 & $\sqrt{ }$ & - & $\sqrt{ }$ & $\sqrt{ }$ & $\sqrt{ }$ & $\sqrt{ }$ \\
\hline
\end{tabular}

From table 2 and 3, it is evident that all of the identified moves appeared in both sets of samples with a high distribution and interestingly the move 'financial performance of the company' appeared in all samples from both sets of the data. In addition, 'concluding the report', 'previewing future and economic condition of the market' were the most widely distributed moves in both sets of samples. However, 'opening the report' and 'reporting on operational performance' were the least frequent moves in both sets of samples. The findings of the present study are compatible with the findings of De Groot (2008), because she also found the moves 'financial performance' and 'future performance' as two of the most highly distributed moves. With regard to the two complimentary moves, she also found that 'reporting on financial performance' is more highly distributed than 'reporting on operational performance'. Although the move distribution in the sample might be an indication of the necessity of certain moves (Bhatia, 1993), the decision, in this regard, could not be limited to the move distribution. Here the communicative purpose of the management foreword also needs to be taken into consideration. Management forewords are written in laymen's term, functioning as corporate communication tool to provide a report of company's past performance plus future plans (Bhatia, 2004; Garzone, 2004; Nickerson \& De Groot, 2005; Plung \& Montgomery, 2004). Considering the purpose of the management foreword, it appears that there exist two main functions: past performance and reporting future plans. The function of past performance consists of two complimentary moves 'reporting on company's operational performance' and 'reporting on company's financial performance'. For the second function that is 'reporting on future plans' there is one move; that is 'previewing future'. Considering the function of writing management forewords, an informative management foreword needs to have these three moves. However, a well-written management foreword also needs to have a brief 'report of economic environment of the market' and a formal 'opening and closing' move. Given the communicative purpose of the management foreword and the move distribution in the samples of the present study, there is an overlap which falls on the move 'reporting the financial performance of the company'. So, it might be possible to conclude that the M3.FP is absolutely necessary for the communicative purpose of management foreword in the studied samples.

\section{Concluding Remarks}

The most interesting finding of the present study was a high degree of regularity with regard to the occurrence of the majority of the moves in management foreword samples from eastern companies. Thereupon, we might be able to consider management foreword as a relatively stable genre. It seems that the Asian companies adopted a standardized approach toward writing their management forewords which is similar to the one used by European companies. In other words, most of the identified moves (M3.FP, M4.OP, M5.FTR and M6.CLS) and some of the move-strategy combinations were already identified by previous studies on management foreword samples of European companies. Considering such similarity, we might be able to argue that there is a mutual understanding among expert members of this discourse community over the conventions of producing management forewords.

The move analysis model proposed by the researcher is an advancement over De Groot (2008) and Nickerson and De Groot (2005) for the following reasons. First, it is exclusively proposed for the management foreword of annual reports and not the other sections of the annual report. Second, the identified strategies within moves are faithful to their moves and do not appear within other moves. Third, identified moves and move-strategy combinations are supported from literature. Fourth, detailed descriptions of the moves are provided. Finally, the analysis for proposing the move model was done on a larger corpus using computerized corpus analysis tool (AntConc 3.3.5w) which increased the reliability of the analysis (Upton, 2002).

However, this study is not free from limitations. The analysis was done on limited samples from Asian companies. There is a need to use the present model in a comparative study between samples from Asian and European as well as American companies to find whether they follow the same conventions. Nevertheless, the fact that there are moves which are common between previous studies (European companies) and present study (Asian companies) might indicate that there is a collective awareness between expert members of this discourse community.

Although the present study is limited in scope, its finding could increase ESP learners' awareness with regard to genre, specifically of management foreword as a business text and guide them to improve their language to communicate more effectively in the business world. According to the literature, the results of genre analysis studies could benefit ESP 
students and provide them with a better understanding of the requirements of a specific genre (Henry \& Roseberry, 1997; 1998; 1999; 2001; Osman, 2004; 2005; 2013). The findings could also function as a business English material for ESP practitioners and increase its authenticity. We hope that business English students could benefit from these findings and could engage more actively in international business communication.

\section{References}

Ary, D., Jacobs, L. C., Razavieh, A., \& Sorensen, C. (2010). Introduction to research in education (8th edition): Singapore: Wadsworth Cengage Learning.

Bhatia, V. K. (1993). Analysing genre: Language use in professional settings. Essex: Longman Group Ltd.

Bhatia, V. (2004). Worlds of written discourse: A genre-based view. New York: Continuum International Publishing Group.

Bhatia, V. K. (2010). Interdiscursivity in professional communication. Discourse \& Communication, 21(1), 32-50.

Bursa Malaysia Berhad. (2013). Main market listing requirement. (2013, September 20), Retrieved from http://www.bursamalaysia.com/market/regulation/rules/listing-requirements/main-market/listing-requirements.

Camiciottoli, B. C. (2010). Earnings calls: Exploring an emerging financial reporting genre. Discourse \& Communication, 4(4), 343-359.

Cho, H., \& Yoon, H. (2013). A corpus-assisted comparative genre analysis of corporate earnings calls between Korean and native-English speakers. English for Specific Purposes, 32(3), 170-185.

Clatworthy, M. A., \& Jones, M. J. (2006). Differential patterns of textual characteristics and company performance in the chairman's statement. Accounting, Auditing \& Accountability Journal, 19(4), 493-511.

Conaway, R. N., \& Wardrope, W. J. (2010). Do their words really matter? Thematic analysis of US and Latin American CEO letters. Journal of Business Communication, 47(2), 141-168.

Connor, U., Davis, K., \& De Rycker, T. (1995). Correctness and clarity in applying for overseas jobs: A cross-cultural analysis of U.S. and Flemish applications. Text, 15(4), 457-476.

Crombie, W., \& Samujh, H. (1999). Negative messages as strategic communication: a case study of a New Zealand company's annual executive letter. Journal of Business Communication, 36(3), 229-246.

De Groot, E., Korzilius, H., Ickerson, C., \& Gerritsen, M. (2006). A corpus analysis of text themes and photographic themes in managerial forewords of Dutch-English and British annual general reports. Professional Communication, IEEE Transactions on, 49(3), 217-235.

De Groot, E. B. (2008). English annual reports in Europe: A study on the identification and reception of genre characteristics in multimodal annual reports originating in the Netherlands and in the United Kingdom. Utrecht: LOT.

Ding, H. (2007). Genre analysis of personal statements: Analysis of moves in application essays to medical and dental schools. English for Specific Purposes, 26(3), 368-392.

Flowerdew, J., \& Wan, A. (2010). The linguistic and the contextual in applied genre analysis: The case of the company audit report. English for Specific purposes, 29(2), 78-93.

Freelon, D. G. (2010).ReCal: Intercoder reliability calculation as a web service. International Journal of Internet Science, 5(1), 20-33.

Glaser, B. G. \& Strauss, A. L. (1967). The discovery of grounded theory: Strategies for qualitative research. New York: Aldine.

Garzone, G. E. (2004). Annual company reports and CEO's letters: Discoursal features and cultural markedness. In C.N. Cadlin \& M. Gotti (Eds.), Iintercultural aspects of specialized communication (pp. 311-341). Bern: Peter Lang.

Garzone, G. E. (2005). Letters to shareholders and chairman's Statements: Textual variability and generic integrity. In P. Gillaerts \& M. GottiBern (Eds.), Genre variation in business letters (pp.179-204 Bern): Peter Lang.

Gray, E. R., \&Balmer, J. M. (1998). Managing corporate image and corporate reputation. Long Range Planning, 31(5), 695-702.

Henry, A., \& Roseberry, R. L. (1997). An investigation of functions, strategies and linguistic features of the introduction and conclusion of the essays. System, 25(4), 479-495.

Henry, A., \& Roseberry, R. L. (1998). An evaluation of a genre-based approach to the teaching of EAP/ESP writing. TESOL Quarterly, Brief Reports and Summaries 32(1), 147-156.

Henry, A., \& Roseberry, R. L. (1999). Raising awareness of the generic structure and linguistic features of the introductions and conclusions of essays. System, 25(4), 479-495.

Henry, A., \& Roseberry, R. L. (2001). Using a small corpus to obtain data for teaching a genre. In M. Ghadessy, A. Henry, \& R.L. Roseberry (Eds.), Small corpus studies and ELT: theory and practice. (pp. 93-113). Philadelphia: John Benjamins North America: Philadelphia.

Holms, R. (1997). Genre analysis and social sciences: An investigation of the structure of the research article dissertation sections in three disciplines. English for Specific Purposes, 16(4), 321-337. 
Hyland, K. (1998). Exploring corporate rhetoric: Metadiscourse in the CEO's letter. Journal of Business Communication, 35(2), 224-244.

Jameson, D. A. (2000).Telling the investment story: A narrative analysis of shareholder reports. Journal of Business Communication, 37(1), 7-38.

Kloptchenko, A., Eklund, T., Karlsson, J., Back, B., Vanharanta, H., \& Visa, A. (2004). Combining data and text mining techniques for analyzing financial reports. Intelligent Systems in Accounting, Finance \& Management, 12(1), $29-41$.

Kohut, G. F., \&Segars, A. H. (1992). The President's letter to stockholders: An examination of corporate communication strategy. Journal of Business Communication, 29(1), 7-21.

Laurence, A. (2012). AntConc: A freeware concordance programe for windows (version 3.3.5w) [computer software]. Retrived July 1, 2012. Available from http://www.antlab.sci.waseda.ac.jp/software.html/

Li, F. (2010). The Information Content of Forward-Looking Statements in Corporate Filings-A Naïve Bayesian Machine Learning Approach. Journal of Accounting Research, 48(5), 1049-1102.

Mobasher, A., Afida, M.A., Abdullah, F., \& Chan, M.Y. (2013). Review of studies on corporate annual reports during 1990-2012. International Journal of Applied Linguistics and Literature, 2(2), 133-141.

Nickerson, N. \& de Groot, E. B. (2005). Dear shareholder, dear stakeholder, dear stockholder: The business letter genre in the annual general report. In P. Gillaerts \& M. Gotti (Eds.), Genre variation in business letters (pp.325-346). Bern: peter Lang.

Nwogu, K. N. (1991). Structure of science popularizations: A genre-analysis approach to the schema of popularized medical texts. English for Specific Purposes, 10(2), 111-123.

Nwogu, K. N. (1997). The medical research paper: Structure and functions. English for Specific Purposes, 16(2), 119138.

Osman, H. (2004). Genre-based instruction for ESP. The English Teacher, 33, 13-29.

Osman, H. (2005). Structural organization and socio-cognitive strategies in university brochures: Implications for ESP. Unpublished Ph.D thesis. University of Malaya, Malaysia.

Osman, H. (2013). Pedagogical genre analysis: A module for copy-writing. English for Specific Purposes World, 13(37), 1-29.

Plung, D. L., \& Montgomery, T. T. (2004). Professional communication: The corporate insiders' approach. Canada: Thomson.

Ripken, S. K. (2005). Predictions, projections, and precautions: Conveying cautionary warnings in corporate forwardlooking statements. University of Illinois Law Review, 2005(4), 929-988.

Rogers, P. S. (2000). CEO presentations in conjunction with earnings announcements extending the construct of organizational genre through competing values profiling and user-needs analysis. Management Communication Quarterly, 13(3), 426-485.

Salmani Nodoushan, M. \& Montazeran, H. (2012). The book review genre: A structural move analysis. International Journal of Language Studies, 6(1), 1-30.

Schmitt, B. H., Simonson, A., \& Marcus, J. (1995).Managing corporate image and identity. Long Range Planning, 28(5), 82-92.

Schröder, H. (1991). Subject-oriented texts: languages for Special Purposes and Text Theory. Berlin: Walter de Gruyter.

Smith, M., \&Taffler, R. J. (2000).The chairman's statement-A content analysis of discretionary narrative disclosures. Accounting, Auditing \& Accountability Journal, 13(5), 624-647.

Spyropoulou, S., Skarmeas, D., \&Katsikeas, C. S. (2010). The role of corporate image in business-to-business export ventures: A resource-based approach. Industrial Marketing Management, 39(5), 752-760.

Stanwick, P. A., \& Stanwick, S. D. (1998). The relationship between corporate social performance, and organizational size, financial performance, and environmental performance: An empirical examination. Journal of Business Ethics, 17(2), 195-204.

Swales, J. M. (1990).Genre analysis: English in academic and research settings. Cambridge: Cambridge University Press.

Swales, J. M. (2004). Research genres: Explorations and applications. Cambridge: Cambridge University Press.

Thomas, J. (1997). Discourse in the marketplace: the making of meaning in annual reports. Journal of Business Communication, 34(1), 47-66.

Upton, T. A. (2002). Understanding direct mail letters as a genre. International Journal of Corpus Linguistics, 7(1), 6585. 